agricultural tests. The most recent work on it is indeed published, paradoxically enough, in the Annals of Eugenics.

"Mathematical Recreations" constitutes an addendum to every mathematical library. I can imagine no better book for a schoolboy or girl who is taking mathematics seriously. The reader will find himself introduced to advanced topics such as topology, group theory, and prime number distribution theory, without any intellectual strain, and will learn a surprising amount of mathematics without knowing it. The more advanced reader will find some novelties in every chapter. Above all, one need not read the book systematically. On the contrary, it is an excellent bedside book into which one can dip at random.

The War may discourage mathematical reading. It need not. I remember that among a row of wounded officers on the deck of a barge in Mesopotamia in 1917, the occupant of the next stretcher to my own was reading Lamb's "Infinitesimal Calculus", whilst I was reading Kelland and Tait's
"Introduction to Quaternions". But systematic study is certainly difficult, and perhaps "Mathematical Recreations" would have been more suitable.

I hope to see many more editions. I may be accused of attempting to gild the lily, but here are two suggestions for the next. Since the theory of Mersenne's and Fermat's numbers is part of the theory of recurring 'decimals' in the scale of 2 , I should like to see an excursus on recurring decimals in the scale of 10 , pointing out, for example, why every recurring decimal with a period of 10 must have 9091 or a multiple in its denominator; and since such formulæ as $\frac{1}{4} \pi=4 \tan ^{-1} 1 / 5-\tan ^{-1} \iota / 239$ are equivalent to factorizations of $n+n \iota$, readers might be introduced to complex arithmetics on p. 348 .

However, Dr. Coxeter knows his job better than I do, and has shown himself a worthy successor of Dr. Rouse Ball. This is the eleventh edition. May there never be a last edition.

\section{J. B. S. Haldane.}

\title{
GENERAL ASTRONOMY
}

\section{(I) Astronomy}

By William T. Skilling and Robert S. Richardson. Pp. $x i+579$. (London : Chapman and Hall, Ltd., 1939). 15s. net.

(2) Exploration du ciel

Par Pierre Rousseau. (Le roman de la science.) Pp. 256. (Paris : Hachette et Cie., 1939.) 20 francs.

(1) THE progress of astronomy, as regards both the methods and results of research, is in these days so rapid that there is always room for a new and up-to-date text-book on the subject. Messrs. Skilling and Richardson's book is the most recent of several that have appeared in the past few years ; and it covers the whole field of descriptive astronomy in a simple style, suitable for the general reader.

The insertion of examination questions at the end of each chapter suggests that the work was intended to afford a complete elementary course for students. Unfortunately its usefulness for this purpose is much impaired by a certain lack of the balance which should characterize a really satisfactory text-book. Thus, while the subject of solar physics is treated in considerable detail (one of the authors being a specialist in this line of research), the planetary system is dealt with in a rather perfunctory way. The minor planets, for example, are dismissed in little more than a single page, while no mention is made of the variable rotation periods of Jupiter and Saturn, or of the transparency of the latter's ring system. On the other hand, the book certainly contains much up-to-date matter of great interest and value to the student. It is well supplied with illustrations, though some of the diagrams are open to criticism. The text appears, apart from a few minor errors and misprints, to be substantially accurate, but the so-called "glossary" at the end of the book is so abbreviated as to be practically useless.

A glance through the names of astronomers quoted in the index will reveal a certain parochialism which is rather common in American scientific books. But it is perhaps a pardonable weakness, and one from which no nation seems to be altogether immune.

(2) M. Rousseau's book consists of a series of popular essays on various aspects of modern astronomy. The author's avowed aim has been to humanize the subject and to emphasize the romantic side of research. To this end he devotes considerable space to the description of the more important astronomical instruments, and of the way in which they are actually used for various purposes. This seems to us a particularly attractive way of dealing with the subject, and $\mathbf{M}$. Rousseau's obvious enthusiasm can scarcely fail to communicate itself to his readers, whether they be possessed of previous astronomical knowledge or not. The book seems worthy of something rather better than its present flimsy cover, and it is a pity that the quality of the paper has ruled out the use of half-tone illustrations.

W. H. Steavenson. 